\title{
Anticipatory Feelings in Intertemporal Choice on Consumption: A Dynamic Experiment
}

\author{
Daniela Di Cagno ${ }^{1}$, Francesco Farina ${ }^{2}$, Amin Z. Ashtiani ${ }^{1}$ \\ ${ }^{1}$ LUISS Guido Carli, Italy \\ ${ }^{2}$ University of Siena, Italy \\ Email: francesco.farina@unisi.it
}

\begin{abstract}
Following the evaluation of anticipatory feelings in Scitovsky's Joyless Economy, we explored a specific interpretation of reversals in intertemporal choice. Anticipatory feelings can be explained as the feeling experienced by the agent while awaiting an upcoming event. We adopted a dynamic experiment where individuals made decisions of consumption at multiple points of time: three experimental sessions in three different dates at two-week intervals. We elicited the initial plans of the same sample in three different sessions over a one-month period and tracked how they implemented their plans as the anticipated event drew closer. The paper innovates with respect to the literature on intertemporal decision making in that the motivation for a varying discount rate, caused by anticipation or procrastination, has been elicited with both monetary and non-monetary (consumption) incentives and within a dynamic setting. We found that anticipatory feeling is a significant possible explanation behind choice reversal. The results remained significant after controlling the other explanatory factors such as risk aversion, uncertainty and time inconsistency.
\end{abstract}

Keywords: Intertemporal decisions, anticipatory feelings, choice reversal.

\section{Introduction}

The systematic anomalies in intertemporal choice detected in Discounted Utility (DU) models (Samuelson 1937), led to the establishment of the Hyperbolic Discounting (HD) model (Laibson, 1997). According to the latter model, dynamic inconsistency results from different evaluations of time (Read, 2001; Prelec, 2004; Rubinstein, 2003).

Although factors such as abstinence and impatience (Warner and Pleeter 2001; Benartzi and Thaler 2004; Brown et al., 2009; Tanaka et al., 2010), risk (Sozou, 1998), and uncertainty (Yaari, 1965; Fernández-Villaverde and Mukherji 2002; Dasgupta and Maskin 2005; Halevy 2008; Manzini and Mariotti 2010), put forward by the HD model can explain the anomalies in intertemporal choice to some extent, there still exist other psychological factors such as sensations and feelings that attribute different utility values to different gains and losses at different times. Recently, the crucial role of psychological factors, also credited in the seminal works by Adam Smith (1759) and David Hume (1739) ${ }^{1}$, has been brought back to attention by the vast literature concerning the impact of emotions on rational choices. After several attempts to connect the economic analysis of anomalies in behavior to the psychological literature (Loewenstein, Prelec, 1992; Caplin, Leahy, 2001; O'Donoghue, Rabin, 2003; Halevi, 2008), the brand-new field of Psychological Game Theory has been launched based on the role of emotions in decision-making (Battigalli, Dufwenberg, 2009).

There are several studies reveal the effect of emotions as an important source of information in decision making (Bagozzi et al., 2000; Clore et al., 2001). The emotion could be originated from the past experiences, upcoming events, or both. There are many researches shod the emotional responses to past

\footnotetext{
${ }^{1}$ Smith shared with Hume the same view on the motivation of decisions. "Pleasure and pain are the great objects of desire and aversion: but these are distinguished not by reason, but by immediate sense and feeling. If virtue, therefore, be desirable for its own sake, and if vice be, in the same manner, the object of aversion, it cannot be reason which originally distinguishes those different qualities, but immediate sense and feeling (A. Smith, 2009(1759), p. 377).
} 
experience (Schoefer, 2008; Williams and Aaker, 2002), future events (MacInnis and de Mello, 2005; Baumgartner et al., 2008; Winterich and Haws, 2011), and mixed emotion experiences (Williams and Aaker, 2002; Richins, 1997; Ruth et al., 2002).

In this study, we aim to explore a specific interpretation of intertemporal choice put forward by behavioral economics, that is the role of anticipatory feelings in choice reversal.

Choice reversal happens when a decision of consumption that has already been made is procrastinated up to the moment in which the increase in anxiety threatens to endanger the increase in pleasure. Here, savoring - the procrastination of consumption as the time of consumption approaches- is clearly fastened to the level of arousal. The slower the rise in anxiety, the more anticipatory feelings are free to feed the savoring, and the longer the increase in pleasure can be procrastinated.

Anticipatory feelings can be explained as the feeling experienced by the agent while awaiting an upcoming event. It includes the anxiety experienced while anticipating a "bad", or the savoring caused by procrastinating a "good". We will argue that ex post choice reversals are not necessarily caused by time-inconsistent preference and the oscillations between cognitive and emotional biases can be accounted for by a variety of motivations.

Uncertainty regarding an upcoming consumption is quite common, especially when potential outcomes are not easily assessed. Bee and Madrigal (2013) show that uncertain consumption situations will elicit anticipatory emotions that inform consumer attitudes and behaviors. Although there are considerable researches in psychology about anticipatory feelings, the evidences over their effect on intertemporal choices are limited (Casari and Dragone 2011a).

This paper attempts to fill this gap by innovating with respect to the literature on emotional decision making and intertemporal choice reversal in that the motivation for a varying discount rate, caused by anticipation or procrastination, has been elicited with both monetary and non-monetary ${ }^{2}$ (consumption) incentives and within a dynamic setting.

In order to test the hypothesis of choice reversal originating from anticipatory feelings, we put forward two methodological strategies.

Whether choice reversal applies both to money and consumption, or the experimental evidence differentiates depending on what is at stake, is still unclear. Even in the case of simple linear utility functions, discount rates for money do not necessarily match the discount rates for consumption (Cubitt and Read, 2007). Furthermore, in some experiments the discount rate of intertemporal choice for money appears to be much less erratic than the one for consumption (Thaler, 1981) ${ }^{3}$. However, in some others, discount rates for money and for a consumption good are highly correlated (Reuben et al., 2011). Since the question still remains whether participants would react differently to different incentives, we elicit individuals' discount rates by testing both for money and consumption goods in the lab ${ }^{4}$.

To overcome the problem of intertemporal choice being elicited at an initial date for all subsequent periods in most experiments, we adopted a dynamic experimental setting (Casari, 2009; Sayman and Öncüler, 2009; Ginè et al., 2012; Read et al., 2012) in which the same group of participants are submitted to an updated but constant series of choices in three different points of time, actually corresponding to their time choices (today, in two weeks and in four weeks). This setting allows to explore whether preferences remain constant as time passes by or subjects' preferences will be reversed because of impatience, self-control and procrastination or by passing through the calendar.

\footnotetext{
${ }^{2}$ Non-monetary rewards, such as noise (Millar and Navarick 1984), rice (Pender 1996), drinking water (Brown et al. 2009), and chocolate (Reuben et al. 2010).

${ }^{3}$ For example, subjects have been asked to specify the amount of money they would require in [one month/one year/ten years] to make them indifferent to receiving $\$ 15$ now. The median responses $[\$ 20 / \$ 50 / \$ 100]$ imply an average (annual) discount rate of 345 percent over a one-month horizon, 120 percent over a one-year horizon, and 19 percent over a ten-year horizon. Yet, Thaler (1981) also found that some people prefer "one apple today" to "two apples tomorrow" but at the same time they prefer "two apples in one year plus one day" to "one apple in one year". ${ }^{4}$ Most intertemporal experiments ask subjects to make decisions over time-dated amounts of money. Thus, they elicit discount rates over stocks of money instead that individual discount rates over utility, and consequently impose to think in terms of stocks of money rather than in terms of the utility of consumption flows.
} 
We adopted a dynamic experiment where individuals made decisions at multiple points of time: three experimental sessions in three different dates at two-week intervals respectively at date 0,1 and 2 . We elicited the initial plans of the same sample of 61 subjects in three different sessions over a one-month period and tracked how they implemented their plans as the anticipated event drew closer. Since this method allows to both elicit subjects' plans and tracks their implementations over time, a better understanding of time inconsistency should ensue. Examples of a dynamic set up in intertemporal decisions are among the others: Della Vigna and Malmendier (2006), Charness and Gneezy (2009), Ariely and Wertenbroch (2002) and Giné et al. (2012). Carbone (2008) offered to experimental subjects' choices among alternative activities (physical exercise, reading a book, eating chocolate, etc.) and latter money allocations.

Moreover, a control group has been introduced in the experiment to detect satiation implications of consumption. Our main findings are:

- We observed substantial deviations from the DU model and its complementary HD model. About $47 \%$ of the experimental subjects chose to postpone the consumption of goods. This violates the DU model. In addition, more than half (57\%) of the subjects reversed their initial choices. These deviations cannot be explained by any of the existing intertemporal decision making models.

- More than half $(58 \%)$ of the participants who reversed their choices during the experiment exhibited anticipatory feelings at least once. We conclude that anticipatory feelings could be a possible explanation for choice reversal.

\section{A Simple Framework of Choice Reversal}

Assume that the life-cycle utility function, presenting the preferences of a subject living $T$ periods, is additively separable. The individual life-cycle utility can then be written as the sum of all discounted one-period utilities:

$$
V_{0}\left(\left[C_{t}\right]_{t=0}^{T}\right)=u\left[C_{0}\right]+\beta \sum_{t=1}^{T} \delta^{t} u\left[C_{t}\right]
$$

where the discount factor is $0<\delta<1$. Exponential discounting applies when $\beta=1$, while hyperbolic discounting applies when and $0<\beta \leqslant 1$. With $\beta<1$, an increasing weight is given to present vis-à-vis to future consumption. Hence, the hyperbolic utility function of the HD model departs from the standard exponential utility function of the DU model because of the value of coefficient $\beta$ (Schwartz and Sheshinsky, 2007). As well-known, a constant rate of discount implied by the DU model is crucial to impose time consistency, whereby the ordering of preferences is invariant to the time of choice. The constancy of the discount rate implies that only abstinence from present utility matters, and that the intertemporal choice is not affected by the amount of money or good at stake. ${ }^{5}$ The anomalies put forward in experiments conducted with the HD model turn down the tenet of "impartiality" in the way a subject evaluates time.

The non-constancy of the discount rate has been almost univocally interpreted as impatience and impulsivity with respect to prospective gains (Strotz, 1956). In equation 1, the individual faces the optimization problem at time $t=0$. A sequence $\left[\mathrm{C}_{\mathrm{t}}\right]_{\mathrm{t}=0}^{\mathrm{T}}$ is the solution, as it reflects his view at this point in time. At $t=1$, in case the individual changes his mind regarding the relative weight of utility in different periods, the sequence changes too. The utility function representing the individual's preferences becomes:

$$
V_{0}\left(\left[C_{t}\right]_{t=0}^{T}\right)=u\left[C_{0}\right]+\beta \sum_{t=2}^{T} \delta^{t} u\left[C_{t}\right]
$$

Let us compare the utility function at $t=0$ in equation 1 with the utility function at $t=1$ in equation 2 . From the comparison between the solution to (1), which is valid for all $t \geqslant 1$, and the solution to (2), which is valid for all $t \geqslant 2$, it is apparent that the product of the $\beta$ and the $\delta$ values in (2) may be different at different points in time. Therefore, the two consumption levels at $t=1$ and at $t=2$ are different as well. To rank the future against the present is a crucial decision at each stage of one's life.

\footnotetext{
${ }^{5}$ Abstinence corresponds to the commitment to be parsimonious in order to save with future needs, which motivates the view whereby the discount (interest) rate is the reward for abstaining from present consumption. The nonconstancy of the discount rate has been interpreted as impatience (and impulsivity) with respect to prospective gains (Strotz, 1956).
} 
In important choices, such as length of job search or early retirement, the individual's intertemporal decision may exhibit a rise or a reduction of the discount rate at any time.

The comparison between equations 1 and 2 indicates that the subject at each date in the future is in the position to revise his life-cycle plan of consumption. The value a subject may be willing to assign to his discounting is open to revision by modifying the value of $\beta \delta$. It is then apparent that the two equations 1 and 2 do not present any obstacle to envisaging that in the subject's intertemporal choice the utility could alternate upswings and downswings over time. The important implication is that whether the choice does occur at an initial date for all subsequent periods - as it is stated in these two models - or in real time - as the real life suggests - is far from irrelevant.

Any rational decision, being a forward-looking attitude by its nature, is prone to changes as time passes and any subject may need to revise the consumption plan according to Bayesian updating, and a new consumption profile is likely to emerge. ${ }^{6}$

In the theoretical literature we can find a variety of interpretations of intertemporal choice, which go beyond the one-direction choice reversal towards the present. The evolution of the subject's intertemporal choice could be conceived of as Markovian strategies of a game between successive selves. The impact of a time delay on intertemporal preference may change, because different selves are in power at different instances of the life-time of the individual. The prevailing interpretation of choice reversal then points to a "bias for the present". Choice reversal towards a lower/shorter-term pay-off has been explained by preference for a commitment aimed at cancelling out uncertainty at the cost of loss of flexibility in the future behaviour (Casari and Dragone, 2015).

The common method employed by the experimentalists to elicit choice reversal is asking subjects questions about their preferences in a static setting. For instance ${ }^{7}$, subjects are asked to choose one of the two available options in the following hypothetical situations which differ only in time horizon:

I. receiving $\$ 100$ today or receiving $\$ 110$ tomorrow;

II. receiving $\$ 100$ in $t$ days and receiving $\$ 110$ in $t+1$ days.

If a subject chooses to receive $\$ 100$ today in (I) and $\$ 110$ in (II), choice reversal is detected. In this example subjects make both decisions in a certain point of time $(\mathrm{t}=0)$. But the question remains whether this preference would remain constant over time, or subject's preference would be reversed after receiving new information over time.

Casari and Dragone (2015) categorized choice reversal into three different types: Static, Dynamic, and Calendar. To illustrate the concept of each type, they apply two consumption goods: $x$ and $y$ and a subject who has three different choices:

- Decision A: at date $t$, choose between consuming $x$ at date $t$ or $y$ at date $t+1$.

- Decision B: at date $t$, choose between consuming $x$ at date $t+1$ or $y$ at date $t+2$.

- Decision $\mathrm{C}$ : at date $t+1$, choose between consuming $x$ at date $t+1$ or $y$ at date $t+2$.

In this framework static choice reversal would be detected if the subject chooses $x$ in $\mathrm{A}$ and $y$ in $\mathrm{B}$ or $y$ in $\mathrm{A}$ and $x$ in $\mathrm{B}$. Inconsistency in preference over time is the central notion of static choice reversal. It can be explained by different levels of impatience over different horizons of time; in other words, when the subject has positive time preference for one horizon of time and a negative time preference for another horizon of time, we witness a reversal of choice.

Another type of choice reversal will be detected if the subject chooses $x$ in $\mathrm{B}$ and $y$ in $\mathrm{C}$ or $y$ in $\mathrm{B}$ and $x$ in C. Casari and Dragone (2015) called it "Dynamic choice reversal".

The third and the last type of choice reversal will be detected when the subject switches his/her preference by passing through the calendar. More precisely, if the subject chooses $x$ in $\mathrm{A}$ and $y$ in $\mathrm{C}$ or $y$ in $\mathrm{A}$ and $x$ in $\mathrm{C}$, then calendar choice reversal will be detected. It might occur when the subject changes his/her preference due to an unexpected event.

In order to test the hypotheses of the origin of choice reversal in anticipatory feelings, we put forward two methodological strategies. First, we point to a deeper understanding of individual intertemporal

6 "Rather than simply maximizing preferences in a limitless fashion, people set goals for themselves, monitor their progress toward those goals, and adjust behavior when they fall short of their goals" (Camerer, Loewenstein, and Prelec,2005, n.13)

7 Thaler, 1981, Thaler, Shefrin, 1981, Frederick et al., 2002. 
choice by eliciting discount rates by testing with both monetary incentive and consumption goods in the lab. Second, we innovate the experimental design by testing the individuals' intertemporal choice in real time.

\section{The Role of Anticipatory Feelings in Intertemporal Choice}

With the seminal 1937 model by Paul Samuelson, and for many decades afterwards, the approach to individual decisions involving time has been a territory carefully controlled by scholars in economics. Though Tibor Scitovsky was an economist, his Joyless Economy (1976) is non-analytical appraisal of utility stemming from pleasure or pain. His book is an attempt to resume psychological motives, such as anticipatory feelings, novelty, arousal and boredom, and put them at the center of the stage in analyzing intertemporal choice.

Scitovsky's analysis of "novelty" can be valuably used to justify "choice reversal" in intertemporal individual behavior - but by postponing consumption, instead of its anticipation forecasted by the HD model - as the effect of the primary influence of the affective system on action. The dominance of emotions in Scitovsky's approach to human behavior is demonstrated by his view whereby any precommitment is rooted in the affective system. The condition for anticipatory feelings complementing the rational deliberation not to behave impulsively, is a high degree of connectedness of the present self with his future selves within the "multiple-self" individual (Parfit, 1984). The higher the degree of connectedness is across selves, the more the "deliberative brain" does not conflict but complements the "emotional brain".

Since the evaluation of future is not depleted in prompting impatience, the subject attaches value to his future wealth or consumption and does not suffer from, but enjoys, procrastination. The slower the rise in anxiety, the more anticipatory feelings are free to feed the savoring and the longer the increase in pleasure can be procrastinated.

The empirical challenge is how to design an experiment that can disentangle the role of anticipatory feelings from the role played by other drivers which are still relevant for intertemporal behavior.

The vast majority of the experimental studies on intertemporal choice have a static setting. The not negligible limit of this kind of experimental design is that the variation in time preference is just detected by way of choices at different dates but subjects choose at the initial date, so that the possibility of choice reversals in both directions is by definition ruled out. Eliciting intertemporal choices in a dynamic setting where subjects choose at multiple dates allows for a deeper understanding of choice reversal. The experimental protocol should be administered by means of an appropriate modelling of sessions to be performed at each date, so that preferences will be elicited at distant time intervals to capture the evolution of time.

Our experimental design tries to build up a setting in which both procrastination and anticipatory feelings were at work and could be in some way disentangled. We elicit the subject's time preference and then verify if at the definite time of consumption, the same choice is maintained, or postponed to a subsequent time.

The hypothesis is that choice reversal towards the present as the decision time approaches occurs less frequently when the intertemporal choice regards a pleasant experience that is at a future date in comparison to a pleasant experiment located in the present. Anticipatory feelings concern the subject's disposition to imagine and savor, thus implying an attitude to postpone an experience of pleasure and anticipate an experience of pain.

We assume that when facing a reward-contingent task to be completed under a deadline, some subjects could prefer postponing the stemming utility. Therefore, we focus our attention on eliciting intertemporal preferences dealing with the desire to accrue money or waiting and savoring the pleasure of experiencing a "physical good". In the next section, we present a multi-stage experimental design inspired by the Scitovsky's analysis of arousal in terms of anticipatory feelings.

\section{The Experimental Design}

We ran three experimental sessions in three different dates at two-week intervals respectively at date 1 , 2 and 3, recruiting the same sample of subjects in the three different sessions over a one-month period. 
61 participants started off the experiment (one subject was removed from the list due to technical issues) of which only 58 accomplished the whole experimental task attending all three sessions ${ }^{8}$.

In each session of the experiment participants face the decision of ranking, on the basis of their preferences, when to consume a "cappuccino and croissant" good in the following way: in Session 1 the available dates were 0 (today), 1 (two weeks later) and 2 (four week later); in session 2 the available dates were 0 (today), 1 (two weeks later); in session 3 just today (Table 1). Since there are three available choices in Session 1 and two available choices in Session 2, we would have six possible rankings in former session (Table 2) and two possible rankings in latter (Table 3).

Table 1. Available dates for consuming good in session 1

\begin{tabular}{l} 
Put in order of preference (1st, 2nd and 3rd) the following alternatives: \\
\hline Consume "cappuccino and croissant" today (immediately at the end of the experiment here in \\
the classroom) $\left(1^{\circ}\right.$ or $2^{\circ}$ or $\left.3^{\circ}\right)$; \\
Consume "cappuccino and croissant" in 15 days (here in the classroom) $\left(1^{\circ}\right.$ or $2^{\circ}$ or $\left.3^{\circ}\right)$; \\
Consume "cappuccino and croissant" in 30 days (here in the classroom) $\left(1^{\circ}\right.$ or $2^{\circ}$ or $\left.3^{\circ}\right)$. \\
\hline
\end{tabular}

Table 2. Ranking of preferred dates for good consumption in session 1

\begin{tabular}{cccccc}
\hline Ranking & Most preferred date & Intermediate preference & Least preferred date & Number & Percentage \\
\hline 012 & Today & Two weeks later & Four weeks later & 26 & $43 \%$ \\
120 & Two weeks later & Four weeks later & Today & 13 & $22 \%$ \\
102 & Two weeks later & Today & Four weeks later & 7 & $12 \%$ \\
210 & Four weeks later & Two weeks later & Today & 7 & $12 \%$ \\
021 & Today & Four weeks later & Two weeks later & 6 & $10 \%$ \\
201 & Four weeks later & Today & Two weeks later & 1 & $2 \%$ \\
\hline Total & & & & 60 & $100 \%$ \\
\hline
\end{tabular}

Table 3. Ranking of preferred dates for good consumption in session 2

\begin{tabular}{ccccc}
\hline Ranking & Most preferred date & Least preferred date & Number & Percentage \\
\hline 12 & Today & Two weeks later & 39 & $67 \%$ \\
21 & Two weeks later & Today & 19 & $33 \%$ \\
\hline Total & & & 58 & $100 \%$ \\
\hline
\end{tabular}

To assure that the ranking is not affected by the time of the experiment (morning), in the sense that our subjects' choices could be affected by their having or not having had breakfast before attending the experiment, in each session we randomly selected (as a control for "satiation") a group of 15 subjects that consumed a "cappuccino and croissant" before the experiment. Since the behavior of those control groups did not significantly differ from that of the others participating in the same session, we assumed that this occurrence did not affect their ranking.

In order to detect the possible effect of anticipatory feelings on the "consumption of a good", at the end of each session we gave a subsample of experimental subjects that preferred to consume their "cappuccino and croissant" "today" (immediately at the end of the experiment in the room where the experiment was run), the possibility to postpone it for one day (Figure 1).

In order to better understand the effect of anticipatory feelings on choice reversal, we elicited individual characteristics such as risk attitudes and intertemporal preferences and disentangled their effects from anticipatory feelings.

To do so, we adopted two well-stated elicitation methods: The Holt and Laury (2002) procedure for risk attitudes and the Andersen et al. (2002) procedure for intertemporal preferences over money for the same periods.

\footnotetext{
8 The Instructions of the experiment is on Online Appendix.
} 


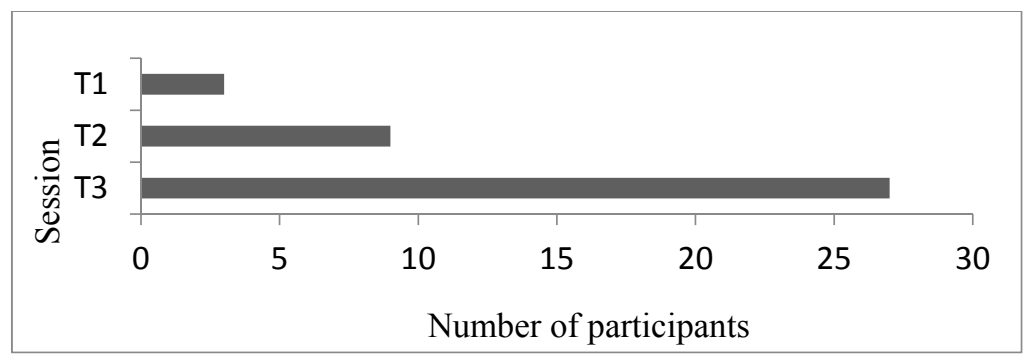

Figure 1. Number of participants who prefer waiting for an additional day (Anticipatory Feelings)

In order to measure risk aversion, Holt and Laury (2002) devised a multiple price list (MPL) design. In this framework, risk attitudes were evaluated by asking subjects to make a series of choices (10 choices) with outcomes that involve some uncertainty: subjects were asked to choose between a riskless and a riskier lottery as reported in Table 4.

Table 4. Risk attitudes

\begin{tabular}{c|cccc|cccc|cc|c}
\hline & \multicolumn{5}{|c|}{ Option A } & \multicolumn{5}{c|}{ Option B } & \multicolumn{2}{c|}{ Expected payoff } & CRRA Interval if \\
Choices & Prob & Payoff & Prob & Payoff & Prob & Payoff & Prob & Payoff & EV $(A)$ & EV $(B)$ & Subject Switches to B \\
\hline 1 & 0.1 & 2.00 & 0.9 & 1.60 & 0.1 & 3.85 & 0.9 & 0.10 & 1,64 & 0,48 & $(-\infty,-1.71)$ \\
2 & 0.2 & 2.00 & 0.8 & 1.60 & 0.2 & 3.85 & 0.8 & 0.10 & 1,68 & 0,85 & $(-1.71,-0.95)$ \\
3 & 0.3 & 2.00 & 0.7 & 1.60 & 0.3 & 3.85 & 0.7 & 0.10 & 1,72 & 1,23 & $(-0.95,-0.49)$ \\
4 & 0.4 & 2.00 & 0.6 & 1.60 & 0.4 & 3.85 & 0.6 & 0.10 & 1,76 & 1,6 & $(-0.49,-0.15)$ \\
5 & 0.5 & 2.00 & 0.5 & 1.60 & 0.5 & 3.85 & 0.5 & 0.10 & 1,8 & 1,98 & $(-0.15,0.14)$ \\
6 & 0.6 & 2.00 & 0.4 & 1.60 & 0.6 & 3.85 & 0.4 & 0.10 & 1,84 & 2,35 & $(0.14,0.41)$ \\
7 & 0.7 & 2.00 & 0.3 & 1.60 & 0.7 & 3.85 & 0.3 & 0.10 & 1,88 & 2,73 & $(0.41,0.68)$ \\
8 & 0.8 & 2.00 & 0.2 & 1.60 & 0.8 & 3.85 & 0.2 & 0.10 & 1,92 & 3,1 & $(0.68,0.97)$ \\
9 & 0.9 & 2.00 & 0.1 & 1.60 & 0.9 & 3.85 & 0.1 & 0.10 & 1,96 & 3,48 & $(0.97,1.37)$ \\
10 & 1.0 & 2.00 & 0.0 & 1.60 & 1.0 & 3.85 & 0.0 & 0.10 & 2 & 3,85 & $(1.37,+\infty)$ \\
\hline
\end{tabular}

In our design, in the first row the expected payoff for lottery A is much larger than the one for lottery B. By proceeding down, the matrix, the expected payoff for lottery B grows greater than the expected payoff for lottery A, although in both cases the expected payoffs increase. Obviously, the expected payoffs for options A and B were not presented to the subjects.

Each subject chose either option A or B in each row and at the end of the experiment we randomly selected one of the rows to be paid off to each subject. Holt and Laury (2002) claim that only risk-lover subjects would choose lottery B in the first row and only risk-averse subjects would choose lottery A in the ninth choice. They called subjects risk neutral if they switch from option A to option B in the fifth choice (since the expected payoff for option A is larger than option B in the first four rows and it changes after choice 5).

The last row just tests if the subjects understand the concepts ${ }^{9}$. Figure 2 shows the distribution of switching points in each session ${ }^{10}$.

The next question is how to interpret the switching points. The first method is to simply assign a binary value to each subject at each session. A subject is risk-averse if she/he switches from lottery A to lottery $\mathrm{B}$ in one of the following choices: 1, 2, 3, 4, 5; and is risk-lover if she/he switches from lottery A to lottery $\mathrm{B}$ in one of the following choices: $6,7,8,9$. The second method is to assign a scaler value between 0 and 10 to each subject by looking at the switching point. The third method employs the constant relative risk aversion (CRRA) characterization to assign an interval to each switching point.

\footnotetext{
${ }^{9}$ It happened only for one subject at session 2 .

${ }^{10}$ Switching point 11 means a subject choose lottery A in all the choices. It actually happened only once at session 1 and once at session 3 .
} 
Holt and Laury (2002) calculate the implied bounds on the CRRA coefficient. In their model, CRRA interval is the dependent variable (Last column of Table 4). Thus, for instance, if a subject switches from $\mathrm{A}$ to $\mathrm{B}$ at choice 5, their CRRA interval would be between -0.15 and 0.14 .

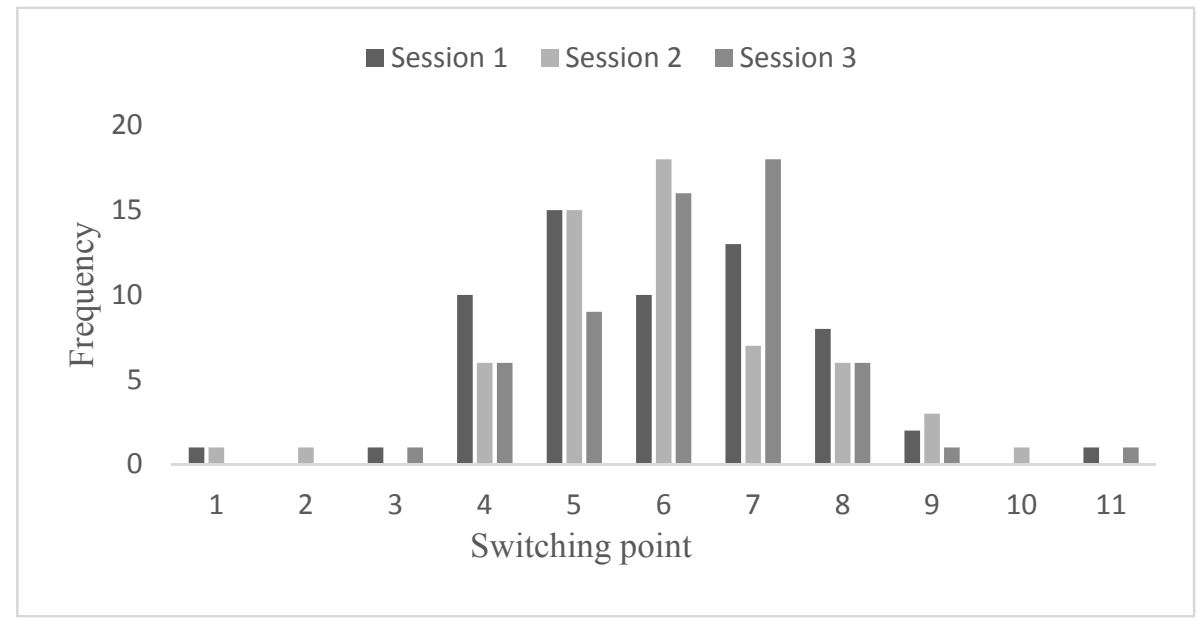

Figure 2. Distribution of switching points in risk aversion lotteries

In this study, we employed Holt and Laury (2002) design by assigning midpoint of each row CRRA interval to related switching point for each subject (inverse distribution functions of switching points for each session are reported in Figure A.2, Appendix).

Table 5. Payoff table of the 1-day horizon

\begin{tabular}{ccccc}
\hline $\begin{array}{c}\text { Payoff } \\
\text { alternative }\end{array}$ & $\begin{array}{c}\text { Payment option A (pays } \\
\text { amount below today) }\end{array}$ & $\begin{array}{c}\text { Payment option B (pays } \\
\text { amount below tomorrow) }\end{array}$ & $\begin{array}{c}\text { Annual interest } \\
\text { rate (in percent) }\end{array}$ & $\begin{array}{c}\text { Preferred payment } \\
\text { option (circle A or B) }\end{array}$ \\
\hline 1 & 200.00 & 200.49 & 3 & A - B \\
2 & 200.00 & 200.82 & 5 & A - B \\
3 & 200.00 & 201.15 & 7 & A - B \\
4 & 200.00 & 201.65 & 10 & A - B \\
5 & 200.00 & 202.07 & 12.5 & A - B \\
6 & 200.00 & 202.48 & 15 & A - B \\
7 & 200.00 & 202.90 & 17.5 & A - B \\
8 & 200.00 & 203.31 & 20 & A - B \\
9 & 200.00 & 204.15 & 25 & A - B \\
10 & 200.00 & 204.99 & 30 & A - B \\
11 & 200.00 & 205.83 & 35 & A - B \\
12 & 200.00 & 206.68 & 40 & A - B \\
13 & 200.00 & 208.38 & 50 & A - B \\
14 & 200.00 & 212.70 & 75 & A - B \\
15 & 200.00 & 217.11 & 100 & A - B \\
16 & 200.00 & 221.60 & 125 & A - B \\
17 & 200.00 & 226.18 & 150 & A - B \\
18 & 200.00 & 230.86 & 175 & A - B \\
19 & 200.00 & 235.63 & 200 & A - B \\
20 & 200.00 & 245.45 & 250 & A - B \\
\hline
\end{tabular}

In order to elicit individual discount rates for money, we employed an experimental design that was first introduced by Coller and Williams (1999) and later expanded by Harrison et al. (2002). In this framework, subjects are asked to choose either A or B in 20 two-optioned choices that differ only in terms of the time when the outcomes will be received (Table 5). This methodology allows to identify the 
individual discount rate by varying the time horizon; In our experiment, time horizons were set according to our consumption setting, i.e. in 1 day, in 15 days, in 16 days, in 30 days and in 31 days. The annual rates adopted were respectively: 3,00\%, 5,00\%,7,00\%, 10,00\%, 12,50\%, 15,00\%, 17,50\%, $20,00 \%, 25,00 \%, 30,00 \%, 35,00 \%, 40,00 \%, 50,00 \%, 75,00 \%, 100,00 \%, 125,00 \%, 150,00 \%, 175,00 \%$, $200,00 \%, 250,00 \%$ (distribution function and inverse distribution functions of switching points for each session are presented in Figures A.3 to A.7 in Appendix). Figure 3 shows the distribution of switching points in each session.

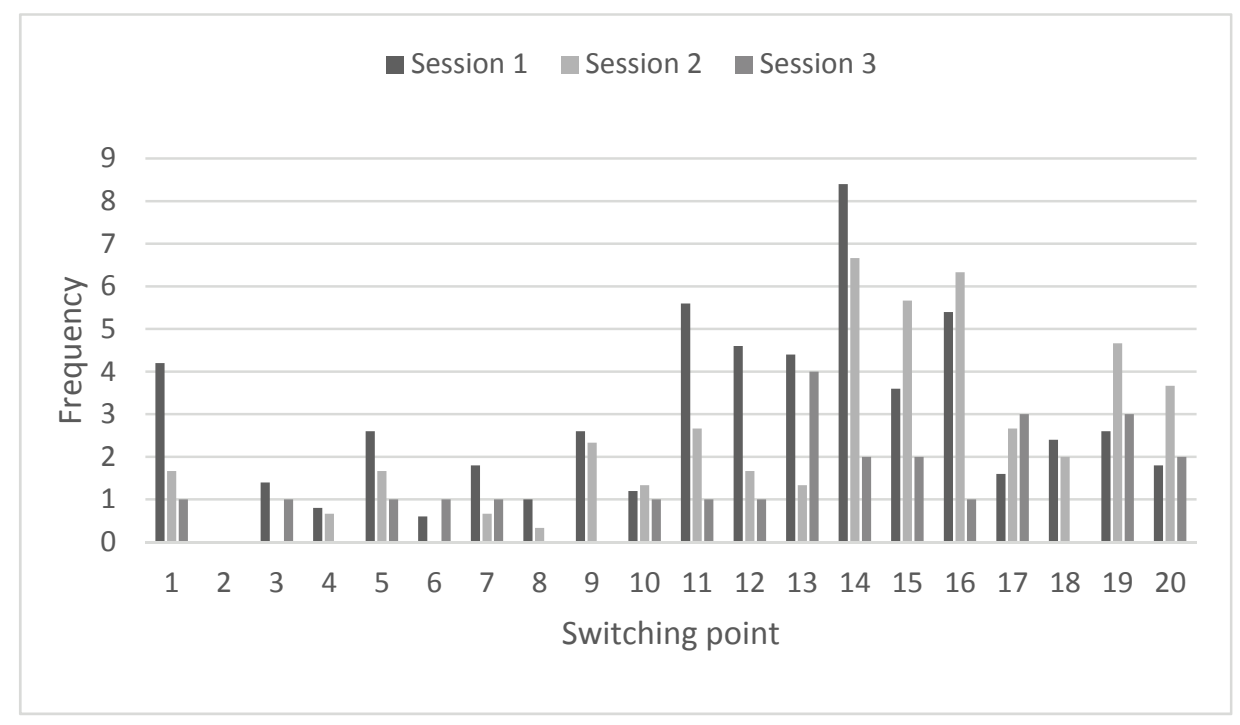

Figure 3. Distribution of switching points in time discounting choices

The first question is: do you prefer to receive $\$ 200$ today or $\$ 200+\mathrm{x}$ in a certain horizon of time? If the subjects prefer the $\$ 200$ today, then we conclude that their discount rate is greater than $\mathrm{x} \%$ per day; otherwise, they have a discount rate smaller than $\mathrm{x} \%$ per day. By gradually increasing $\mathrm{x}$ in the next 19 questions, we were able to elicit discount rate more precisely.

For subjects who chose option $\mathrm{A}$ in choices 0 to 5 and option $\mathrm{B}$ in choices 6 to 20, we calculated a discount rate of between $12.5 \%$ and $15 \%$.

Since in this method the discount rate is not explicitly observed for every given individual, and only intervals of discount rates are detected, both Coller and Williams (1999) and Harrison et al. (2002) used interval-censored methods. In this study, we considered the midpoint of interval as a scaler value for related switching point.

Table 6. Mean of discount rate (in percentage)

\begin{tabular}{ccccccc}
\hline & 1-day & 15-day & 16-day & 30-day & 31-day & Mean \\
\hline Session 1 & 115 & 67 & 72 & 75 & 81 & 82 \\
Session 2 & 178 & 122 & 115 & & & 139 \\
Session 3 & 203 & & & & & 203 \\
\hline All sessions & & & & & 141 \\
\hline
\end{tabular}

Table 6 shows the mean of discount rates corresponding to each time horizon for each session. The mean of discount rate is relatively higher for day1 comparing to other time horizons in all sessions. The 
results are consistent with hyperbolic discount model. The mean of discount rate for all the subjects in each session are $82 \%, 139 \%$, and $203 \%$ for session 1,2 , and 3 respectively (Table 6). ${ }^{11}$

\section{Sample, Procedures and Incentive}

Our experimental sample is composed of 58 undergraduate freshmen of Economics at Luiss University of Rome, of which 35 are males and 23, females. Most of them come from the Centre of Italy (40 out of 58) and the remaining come from the South (18 out of 58). Our experimental sessions were all conducted in Aula Polivalente of Luiss Guido Carli University of Rome so that the logistics would be minimized.

We incentivized our subjects separately for each of the three tasks they performed during the experimental session. As for risk attitude, we randomly selected one of the lotteries the subject had chosen and we allowed each of them to extract the corresponding payment from an urn accordingly prepared. For intertemporal rates, we randomly selected one of the time horizons proposed and then one out of the 20 choices and we paid them the outcome corresponding to their actual choice (in experimental tokens). As for consumption, we gave them the possibility to consume their "croissant and cappuccino" at the preferred date. Our subjects gained from the experiment an average of 8 euro per session ( 3 in goods and 5 in money), getting an overall payment of about 24 euro per subject.

\section{Results}

In this section we discuss our results in depth. First, we present the preferred profiles for good consumption and then examine how subjects' preferences might revers during the experiment. Finally, we explore the causes of choice reversal by concentrating on the role of anticipatory feelings.

In session 1, about half (47\%) of the experimental subjects chose to postpone receiving the consumption good to the future sessions (34\% to session 2 and $14 \%$ to session 3). The results are in contrast with the primary assumption which notes that subjects would prefer immediate pleasure (we assume that subjects receive pleasure by consuming the good). Clearly, the results cannot be explained by discounting utility functions (either exponential or quasi hyperbolic discounting models). According to discounting utility functions, the best choice for a subject is to prefer the closer future rather than further future (i.e. 012 rather than the other choices).

Table 7. Preferred dates chosen by subjects

\begin{tabular}{ccccc}
\hline & Most preferred date & Intermediate & Least preferred & \\
\hline Today & $55 \%$ & $13 \%$ & $32 \%$ & $100 \%$ \\
In two weeks & $32 \%$ & $55 \%$ & $13 \%$ & $100 \%$ \\
In four weeks & $13 \%$ & $32 \%$ & $55 \%$ & $100 \%$ \\
\hline
\end{tabular}

The results presented in Table 2 reveal that only $43 \%$ of subjects chose this profile. By comparing the preferred profile between today and in four weeks (Table 7), we noticed that although $55 \%$ of subjects preferred to consume immediately (012 and 021), 13\% of them preferred to consume in four weeks (201 and 210). Moreover, $68 \%$ of the subjects' preferences are compatible with a stochastic utility model (210 and 201 and 012 and 102). By comparing the profiles who preferred to consume in two weeks to those who preferred to consume in 4 weeks, however, we noticed that $24 \%$ of the subjects preferred to consume in four weeks (201 and 210 and 021) rather than in two weeks (120 and 102 and 012).

\footnotetext{
${ }^{11}$ In another attempt, we assigned a binary value for each decision: if a subject switch from option A to option B before choice 15 (when the annual discount rate is less than 100\%) this subject is called impatient in this decision making, otherwise the subject is patient. We elicited this binary value for each subject for each session in all horizons of time. Figure A.1 in Appendix shows the percentage of impatient subject in any decision making. In addition, the tables report the results in more detail when we divided the subjects into 2 different categories: Men/Women and Risk averse/Risk lovers.
} 
Therefore, discounted utility model does not seem to be a sufficient model for explaining the subjects' intertemporal choices. It only explains $43 \%$ of the subjects' preferences in our experiment.

\subsection{Detecting Choice Reversal}

In the experiment $57 \%$ of subjects show at least one type of choice reversal. Casari and Dragone (2015) discuss that when one type of choice reversal is observed, at least another type is inevitably present as well. For instance, if a static choice reversal is detected, we should expect either dynamic or calendar choice reversal as well. Moreover, they show that it is not possible to detect all types of choice reversal simultaneously. Hence, for each subject we will expect to detect either no choice reversal or exactly two types simultaneously. In our experiment, $43 \%$ of subjects did not exhibit any form of choice reversal. They either chose profile 012 in session 1 and 12 in session 2, or chose profile 210 in session 1 and 21 in session 2.

The preferences of the first group can be explained by the discounting utility model. They do not show any form of procrastination and, thus, closer gratification is the most preferred date for this group. The second group did not exhibit any type of choice reversal either. However, their preferences over consumption good were exactly in the opposite direction of the first group. They exhibited a negative time preference utility function and preferred further gratification. Only $7 \%$ of the subjects had this preferred profile.

Table 8 reports that about $47 \%$ of participants exhibited static choice reversal. As we mentioned before, this reversal of choice points to a bias for the present. In the experiment, static choice reversal is detected when a subject shows any kind of inconsistency over preference in session 1 (preferred profiles 021, 201, 120, 102).

Table 8. Different forms of choice reversal

\begin{tabular}{lcc}
\hline & $N$ & Percent \\
\hline Static choice reversal (T1) & 27 & $47 \%$ \\
Calendar choice reversal (T1 and T2) & 21 & $36 \%$ \\
Dynamic choice reversal (T2 and T3) & 18 & $31 \%$ \\
Subjects show at least one form of choice reversal & 33 & $57 \%$ \\
Subjects show no any form of choice reversal & 25 & $43 \%$ \\
Sum & 58 & $100 \%$ \\
\hline
\end{tabular}

Table 9. Frequency of preferred profiles

\begin{tabular}{ccccccc}
\hline $\begin{array}{c}\text { Preference } \\
\text { in session 1 }\end{array}$ & $\begin{array}{c}\text { Preference } \\
\text { in session 2 }\end{array}$ & $\begin{array}{c}\text { Static Choice } \\
\text { Reversal }\end{array}$ & $\begin{array}{c}\text { Dynamic Choice } \\
\text { Reversal }\end{array}$ & $\begin{array}{c}\text { Calendar } \\
\text { Choice Reversal }\end{array}$ & $\begin{array}{c}\text { Number of } \\
\text { subjects }\end{array}$ & $\begin{array}{c}\text { Percentage } \\
\text { of subjects }\end{array}$ \\
\hline $0,1,2$ & 1,2 & No & No & No & 21 & $36 \%$ \\
$0,1,2$ & 2,1 & No & Yes & Yes & 3 & $5 \%$ \\
$0,2,1$ & 1,2 & Yes & No & Yes & 4 & $7 \%$ \\
$0,2,1$ & 2,1 & Yes & Yes & No & 2 & $3 \%$ \\
$1,0,2$ & 1,2 & Yes & Yes & No & 5 & $9 \%$ \\
$1,0,2$ & 2,1 & Yes & No & Yes & 2 & $3 \%$ \\
$1,2,0$ & 1,2 & Yes & Yes & No & 5 & $9 \%$ \\
$1,2,0$ & 2,1 & Yes & No & Yes & 8 & $14 \%$ \\
$2,0,1$ & 1,2 & Yes & No & Yes & 1 & $2 \%$ \\
$2,0,1$ & 2,1 & Yes & Yes & No & 0 & $0 \%$ \\
$2,1,0$ & 1,2 & No & Yes & Yes & 3 & $5 \%$ \\
$2,1,0$ & 2,1 & No & No & No & 4 & $7 \%$ \\
\hline
\end{tabular}

Moreover, about $36 \%$ of subjects exhibited calendar choice reversal. In our setting, if a subject switches its preferred profile by passing from session 1 to session 2 , we will observe the occurrence of calendar choice reversal. 
In addition, we observed that about $31 \%$ of subjects exhibited dynamic choice reversal which mostly points to self-control problems and procrastination. Table 9 (according to Casari and Dragone (2015)) reports under which scenario each type of choice reversal might happen. In conclusion, $57 \%$ of subjects show at least one form of choice reversal. The question is how to explain this occurrence.

\subsection{The Role of Anticipatory Feelings}

As we explained in section 3, at the end of each session we gave to the experimental subjects that preferred to consume "today" their "cappuccino and croissant" (immediately at the end of the experiment in the room where the experiment was run) the possibility to postpone it by one day. We put this feature in the experiment in order to detect the effect of anticipatory feelings on the postponement of receiving the reward. Subjects were insured that they would receive the primary reward without any uncertainty. The results reveal that $52 \%$ of subjects preferred to postpone consumption of the good at least for one session.

More importantly, for $58 \%$ of the subjects who exhibited choice reversal, an anticipatory feeling was as well detected at least once. This suggests that anticipatory feelings (in this case postponing the savoring) can be a possible explanation for choice reversal. To better understand how and to which extent choice reversal is influenced by anticipatory feelings, we use regression analysis.

Table 10 illustrates the results of a probit regression to explain reversal in preferences. In this model, the dependent variable, which is a binary variable, equals 1 when an individual shows at least one form of choice reversal; and equals zero, otherwise. The main explanatory variable is anticipatory feelings. We collected data from 58 subjects per session, thus, we have a total of 174 observations for anticipatory feelings (AF) in our panel data model. $A F_{t}$ equals 1 when a subject prefers to postpone the primary reward to one day later (exhibits anticipatory feeling) in session $t(t=1,2$, and 3 ).

Table 10. probit regression outcome

\begin{tabular}{|c|c|c|c|c|}
\hline \multicolumn{5}{|c|}{$\begin{array}{l}\text { Dependent Variable: equals } 1 \text { if an individual show at least one form of choice reversal; and } \\
\text { equals zero, otherwise. }\end{array}$} \\
\hline Model & (1) & (2) & (3) & (4) \\
\hline Anticipatory feelings & $.418^{* *}$ & $.444^{*}$ & .384 & $.497^{* *}$ \\
\hline (A dummy for each session) & $(.236)$ & $(.239)$ & $(.237)$ & $(.246)$ \\
\hline \multirow{2}{*}{ Mean Discount Rate } & & $-.002^{* *}$ & & $-.002^{* *}$ \\
\hline & & $(.0009)$ & & $(.001)$ \\
\hline \multirow{2}{*}{$\begin{array}{l}\text { Risk Aversion } \\
\text { (A dummy for each session) }\end{array}$} & & & .072 & .036 \\
\hline & & & $(.200)$ & $(.212)$ \\
\hline \multirow{2}{*}{ Satiation } & & & & .326 \\
\hline & & & & $(.239)$ \\
\hline \multirow{2}{*}{ Gender } & & & & .245 \\
\hline & & & & $(.207)$ \\
\hline \multirow{2}{*}{ Region } & & & & .267 \\
\hline & & & & $(.213)$ \\
\hline \multirow{2}{*}{ Constant } & .083 & $.376^{* *}$ & .087 & .363 \\
\hline & $(.108)$ & $(.171)$ & $(.131)$ & $(.239)$ \\
\hline $\mathrm{N}$ & 174 & 174 & 171 & 171 \\
\hline Pseudo $\mathrm{R}^{2}$ & 0.0135 & 0.0341 & 0.0123 & 0.0515 \\
\hline Log likelihood & -117.347 & -114.890 & -114.956 & -110.388 \\
\hline \multicolumn{5}{|l|}{ Notes: Probit estimation } \\
\hline
\end{tabular}

Model 1 reveals a positive and significant correlation between choice reversal and anticipatory feelings. It confirms our hypothesis that anticipatory feelings are partially able to explain reversal in preferences. Obviously, this correlation does not show much if we do not consider other factors that might contribute 
to choice reversal. Therefore, we added control variables to the initial model: discount rate, risk aversion, and some demographic variables.

Model 2 shows the regression outcome when we add discount rate to the model. The regression coefficient of anticipatory feelings remains statistically significant at $1 \%$ level. The regression coefficient of discount rate reveals a negative and statistically significant correspondence between discount rate and choice reversal. According to these results, the subjects who discount time in a higher rate (more impatient people), are more likely to reverse their choices. The results confirm the previous findings in the literature.

Model 3 shows the results of regression after controlling for risk aversion variable (RA). For each experimental subject, $R A_{t}$ equals 1 for risk-lover and equals 0 for risk-averse subjects in session $t(t=1,2$, and 3). The coefficient is not anymore statistically significant, neither for anticipatory feelings, nor for risk aversion. We conclude that, in our experiment, choice reversal is not influenced by the level of risk aversion. ${ }^{12}$

Finally, in Model 4 we added some other control variables: satiation, gender, and the place of birth. The results in Model 4 show that none of the new variables affect our primary results; anticipatory feelings still remain significant in explaining choice reversal.

\section{Conclusion}

Our attempt in this paper was to broaden the range of possible explanations for choice reversal by presenting experimental evidence of the role of anticipatory feelings in choice reversal.

The experiment's outcome reveals that about $52 \%$ of subjects show anticipatory feelings at least once, and more interestingly, $58 \%$ of subjects who reversed their choices exhibited anticipatory feelings at least once. We conclude that anticipatory feelings might be a possible explanation for choice reversal.

In order to better understand how individual characteristics could affect the possible existence of anticipatory feelings, we elicited separately both individuals' risk attitudes and intertemporal preferences. By adding these variables to the model, we noticed that although discount rate over money is a strong explanation for reversal of preference, it does not refute the relevance of our findings about the influence of anticipatory feelings on choice reversal.

The results are important for consumers, companies, and researches. For the consumer could be indicated as a good contribution to extend the knowledge on making informed decisions. The results may lead to questioning the excess of information that is demanded to market, arguing informed decision making. For companies and researchers, they should be invited to consider the role of anticipatory feelings as an important factor in consumer decisions that might be reversed by stimulus of consumption a good.

\section{References}

1. Andersen et al. (2002), Human Aggression, Annu. Rev. Psychol. 2002. 53:27-51.

2. Ariely, D., K. Wertenbroch, "Procrastination, Deadlines and Performance: Self-control by precommittment", Psycological Science, 13: 219-224, 2002.

3. Bagozzi RP, Baumgartner H, Pieters R, Zeelenberg M. 2000. The role of emotions in goal directed behavior. In Ratneshwar S, Mick DG, Huffman C (eds). The Why of Consumption: Contemporary Perspectives on Consumer Motives, Goals, and Desires. Routledge: London, UK; 36-58.

4. Battigalli, P., M. Dufwenberg, "Dynamic psychological games," Journal of Economic Theory, vol. 144(1), 1-35, 2009.

5. Baumgartner H, Pieters R, Bagozzi RP. 2008. Future-oriented emotions: conceptualization and behavioral effects. European Journal of Social Psychology 38: 685-696.

\footnotetext{
${ }^{12}$ As we described in session 2.3, in order to interpret the switching points, we can also employ the constant relative risk aversion (CRRA) characterization to assign an interval to each switching point (Holt and Laury, 2002). We used the same method and replace the binary variables by scaler ones and ran the same regression models. The results (presented in Table A.1) confirm our primary outcomes.
} 
6. Bee and Madrigal (2013), Consumer uncertainty: The influence of anticipatory emotions on ambivalence, attitudes, and intentions, Journal of Consumer Behaviour, J. Consumer Behav. 12: 370-381 (2013)

7. Benartzi, S., \& Thaler, R. H. (2004). Save more tomorrow: using behavioral economics to increase employee saving. Journal of Political Economy, 112, S164-S187.

8. Brown, A. L., Chua, Z. E., \& Camerer, C. F. (2009). Learning and visceral temptation in dynamic saving experiments. The Quarterly Journal of Economics, 124, 197-223.

9. Camerer C., G. Loewenstein, D. Prelec, "Neuroeconomics: How Neuroscience Can Inform Economics", Journal of Economic Literature, 43: 9-64, 2005.

10. Caplin A., J. Leahy, "Psychological Expected Utility", Quarterly Journal of Economics,116: 55-79, 2001.

11. Carbone, E., "Temptations and Dynamic Consistency", Theory and Decision, 64: 229-248, 2008.

12. Casari M. , D. Dragone "Choice reversal without temptation: A dynamic experiment on time preferences", J Risk Uncertain (2015) 50:119-140, 2015.

13. Casari, M. (2009). Precommitment and flexibility in a time-decision experiment. Journal of Risk and Uncertainty, 38, 117-141.

14. Casari, M., \& Dragone, D. (2011a). On negative time preferences. Economics Letters, 111, 37-39.

15. Charness, G. , U. Gneezy, "Incentives to Exercise", Econometrica, 7: 909-931, 2009.

16. Clore GL, Gasper K, Garvin E. 2001. Affect as information. In Forgas JP (ed.). Handbook of Affect and Social Cognition. Lawrence Erlbaum Associates: Mahwah, NJ; 121-144.

17. Coller, M. ,M.B. Williams, "Eliciting Individual Discount Rates", Experimental Economics, 2: 107-127, 1999.

18. Cubitt, R. P. , D. Read, "Can Intertemporal Choice Experiments Elicit Time Preferences for Consumption?", Experimental Economics, 10: 369-389, 2007.

19. Dasgupta, P., \& Maskin, E. (2005). Uncertainty and hyperbolic discounting. American Economic Review, 95, 1290-1299.

20. Della Vigna S., U. Malmendier, "Paying not to go to the Gym", American Economic Review, 96, 694-719, 2006.

21. Elster J., G. Loewenstein "Utility from memory and anticipation", in Elster J., Loewenstein G, (eds) Choice over time NY, USA: Russell Sage Foundation; pp. 213-234, 1992.

22. Fernández-Villaverde, J., \& Mukherji, A. (2002). Can we really observe hyperbolic discounting? PIER Working Paper No. 02-008.

23. Frederick S., G. Loewenstein "Conflicting motives in evaluations of sequences", Journal of Risk and Uncertainty 37: 221-235, 2008.

24. Frederick, S., G. Loewenstein, T. O'Donoghue, "Time Discounting and Time Preference: A Critical Review", Journal of Economics Literature, 40(2): 351-401, 2002.

25. Giné X., J. Goldberg, D. Silverman, D. Yang, "Revising commitments: Field evidence on the adjustment of prior choices", NBER WP n.18065, 2012.

26. Halevy Y. "Strotz Meets Allais: Diminishing Impatience and the Certainty Effect", American Economic Review, 98: 3, 1145-1162, 2008.

27. Harrison, G. W., M.I. Lau, M.B. Williams, "Estimating Individual Discount -33- Rates for Denmark: A Field Experiment," American Economic Review, 92(5), December 2002, 1606-1617.

28. Holt, C. A., , Laury, S. K., "Risk Aversion and Incentive Effects," American Economic Review, 92(5), 2002.

29. Karen Page Winterich, Kelly L. Haws, Helpful Hopefulness: The Effect of Future Positive Emotions on Consumption, Journal of Consumer Research, Volume 38, Issue 3, 1 October 2011, Pages 505-524, https://doi.org/10.1086/659873

30. Laibson, D. (1997). Golden eggs and hyperbolic discounting. Quarterly Journal of Economics, 112, 443-77.

31. Loewenstein G, Prelec D. "Anomalies in intertemporal choice: Evidence and an interpretation", Quarterly Journal of Economics, 107: 573-597, 1992.

32. Loewenstein G., S. Frederick, T. O'Donoghue, "Time Discounting and Time Preference: A Critical Review", Journal of Economic Literature, 40: 351-401, 2002.

33. Loewenstein G., T. O’Donoghue, "Animal Spirits: Affective and Deliberative Processes in Economic Behavior", Working Paper Cornell University, Center for Analytical Economics, 2004.

34. MacInnis DJ, de Mello GE. 2005. The concept of hope and its relevance to product evaluation and choice. Journal of Marketing 69: 1-14.

35. Manzini, P., \& Mariotti, M. (2010). Moody choice. IZA Discussion Paper 5005.

36. Metcalfe J., W. Michel "A Hot/Cool-System Analysis of Delay of Gratification: Dynamics of Willpower", Psychological Review, 106: 3-19, 1999. 
37. Millar, A., \& Navarick, DJ (1984). Self-control and choice in humans: effects of video game playing as a positive reinforcer. Learning and Motivation, 15, 203-218.

38. O'Donoghue T., Rabin M. "Self awareness and self control" in Loewenstein G, Read D, Baumeister R.F. (eds) Time and Decision: Economic and Psychological Perspectives on Intertemporal Choice, New York, Russell Sage Foundation, 217-243, 2003.

39. Parfit, D., Reasons and Persons, Oxford University Press, 1984.

40. Patti Williams, Jennifer L. Aaker, Can Mixed Emotions Peacefully Coexist?, Journal of Consumer Research, Volume 28, Issue 4, March 2002, Pages 636-649, https://doi.org/10.1086/338206

41. Pender, J. L. (1996). Discount rates and credit markets: theory and evidence from rural India. Journal of Development Economics, 50, 257-296.

42. Prelec D. "Decreasing Impatience: A Criterion for Non-stationary Time Preference and 'Hyperbolic Discounting'", Scandinavian Journal of Economics, 106(3): 511-532., 2004.

43. Read D., "Is time-discounting hyperbolic or subadditive?", Journal of Risk and Uncertainty, 23: 5-32, 2001.

44. Read, D., Frederick, S., \& Airoldi, M. (2012). Four days later in Cincinnati: longitudinal tests of hyperbolic discounting. Acta Psychologica, 140, 177-185.

45. Reuben E., P. Sapienza, and L. Zingales, "Time discounting for primary and monetary rewards", Economic Letters, vol. 106(2):125-127, 2011.

46. Richins ML. 1997. Measuring emotions in the consumption experience. Journal of Consumer Research 24: 127146.

47. Rubinstein A. "Economics and Psychology. The Case of Hyperbolic Discounting", in International Economic Review, 44: 1207-1216, 2003.

48. Ruth JA, Brunel FF, Otnes CC. 2002. Linking thoughts to feelings: investigating cognitive appraisals and consumption emotions in a mixed-emotions context. Journal of the Academy of Marketing Science 30: 44-58.

49. Samuelson P.A., "A note on measurement of utility", Review of Economic Studies, 4: 155-161, 1937.

50. Sayman, S., \& Öncüler, A. (2009). An investigation of time inconsistency. Management Science, 55, 470-482.

51. Schoefer K. 2008. The role of cognition and affect in the formation of customer satisfaction judgements concerning service recovery encounters. Journal of Consumer Behaviour 7: 210-221.

52. Schwarz, Mordechai E. \& Sheshinski, Eytan, 2007. "Quasi-hyperbolic discounting and social security systems," European Economic Review, Elsevier, vol. 51(5), pages 1247-1262, July.

53. Scitovsky T., The Joyless Economy, Oxford Economic Press, Oxford, 1976.

54. Sozou, P. D. (1998). On hyperbolic discounting and uncertain hazard rates. Proceedings of the Royal Society of London: Biological Sciences (Series B), 265(1409), 2015-2020.

55. Strotz R.H., "Myopia and Inconsistency in Dynamic Utility Maximization", Review of Economic Studies, 23 : 165-180, 1956.

56. Tanaka, T., Camerer, C., \& Nguyen, Q. (2010). Risk and time preferences: linking experimental and household survey data from Vietnam. American Economic Review, 100, 557-571.

57. Thaler R.H., "Some Empirical Evidence on Dynamic Inconsistency", Economics Letters, 8: 201-7, 1981.

58. Thaler R.H., H.M. Shefrin "An Economic Theory of Self-Control", Journal of Political Economy, 89: 392-410, 1981.

59. Warner, J. T., \& Pleeter, S. (2001). The personal discount rate: evidence from military downsizing programs. American Economic Review, 91, 33-53.

60. Yaari, M. (1965). Uncertain lifetime, life insurance, and the theory of the consumer. Review of Economic Studies, 32, 137-150. 